\title{
Electrochemical Oxidation of an Immunosuppressant, Mycophenolate Mofetil, and Its Assay in Pharmaceutical Formulations
}

\author{
S. N. Prashanth, ${ }^{1}$ K. C. Ramesh, ${ }^{2}$ and J. Seetharamappa ${ }^{1}$ \\ ${ }^{1}$ Department of Chemistry, Karnatak University, Dharwad 580003 , India \\ ${ }^{2}$ Department of Chemistry, SJM College, Chitradurga 577 501, India \\ Correspondence should be addressed to J. Seetharamappa, j_seetharamappa@rediffmail.com
}

Received 9 June 2011; Revised 21 July 2011; Accepted 1 August 2011

Academic Editor: Emmanuel Maisonhaute

Copyright ( $) 2011$ S. N. Prashanth et al. This is an open access article distributed under the Creative Commons Attribution License, which permits unrestricted use, distribution, and reproduction in any medium, provided the original work is properly cited.

\begin{abstract}
Electrochemical oxidation of mycophenolate mofetil (MMF) has been studied at a glassy carbon electrode in aqueous solution over a wide $\mathrm{pH}$ range. MMF was oxidized on glassy carbon electrode (GCE) by an irreversible process that was controlled mainly by diffusion. The irreversibility of the electrode process was verified by different criteria. A probable mechanism for electrochemical oxidation of MMF was proposed. Differential-pulse voltammogram of the drug showed two oxidation peaks at $0.631 \mathrm{~V}$ and at $0.921 \mathrm{~V}$ (verses SCE) in phosphate buffer of $\mathrm{pH}$ 6.0. This process could be used to determine MMF in the concentration range of $5.0 \times 10^{-7}$ to $7.5 \times 10^{-4} \mathrm{M}$ with a limit of detection of $1.48 \times 10^{-7} \mathrm{M}$. The method was successfully applied for the analysis of MMF in pure and dosage forms and in biological fluids.
\end{abstract}

\section{Introduction}

Mycophenolate mofetil (MMF), chemically known as (Z)2-morpholinoethyl6-(4-hydroxy-7-methoxy-7-methyl-3oxo-1,3-dihydroisobenzofuran-5-yl)-4-methylhex-4-enoate, is rapidly absorbed following oral administration and hydrolyzed to its active metabolite, mycophenolic acid (MPA). It is a reversible inhibitor of inosine monophosphate dehydrogenase (IMPDH) and thus inhibits purine synthesis [1], with potent cytostatic effects on both $\mathrm{T}$ and $\mathrm{B}$ lymphocytes. The plasma halflife of MPA is approximately $16 \mathrm{~h}$. It is used for the prophylaxis of graft rejection in kidney [2], heart [3], and liver transplantation [4], and it has also been used after transplantation of the lung [5], pancreas [6], and intestines [7]. It has also been tried for the prophylaxis of graft-versus-host disease after bone marrow transplantation [8]. Due to the clinical advantages of MMF, there has been an increase in the number of MMF formulations in the market in recent years [9].

A few analytical methods namely, HPLC [10-14], LC-MS [14], spectrophotometric [15], and micellar electrokinetic chromatographic [16] have been reported for the determination of MMF in bulk, pharmaceutical formulations, and biological samples. The reported chromatographic and spectroscopic methods were found to be time consuming. This prompted us to develop a simple, rapid, and costeffective analytical method for routine analysis. Literature survey revealed that no electrochemical method was reported to date for the estimation of MMF in bulk drug and formulations. In the present study, we report a simple, precise, accurate, and economically viable electrochemical method for the estimation of MMF in bulk and pharmaceutical formulations, and in biological fluids. Statistical tests were performed for validation of data.

\section{Experimental}

2.1. Apparatus. Electrochemical studies were carried out on a CHI-1103a electrochemical analyzer (CH Instruments Ltd., Co., USA, version 9.03) electrode system involving a GCE ( $3 \mathrm{~mm}$ diameter) as the working electrode, a platinum wire as 
TABLE 1: Characteristics of calibration plot of MMF.

\begin{tabular}{lc}
\hline & DPV \\
\hline Linearity range $(\mu \mathrm{M})$ & $0.5-750$ \\
LOD $(\mu \mathrm{M})$ & 0.148 \\
LOQ $(\mu \mathrm{M})$ & 0.494 \\
Interday assay RSD* $(\%)$ & 1.51 \\
Intraday assay RSD* $(\%)$ & 1.24 \\
\hline
\end{tabular}

${ }^{*}$ Average of 5 determinations.

a counter electrode, and a saturated calomel electrode (SCE) as reference electrode.

2.2. Reagents. Pure MMF was obtained as a gift sample from Dr. Reddy's Laboratories, India. Tablets were obtained from local sources commercially. A stock solution of MMF $(2.5 \mathrm{mM})$ was prepared in a mixture containing water and methanol $(50: 50)$ and stored in a refrigerator at $4^{\circ} \mathrm{C}$. In the present study, phosphate buffer $(\mathrm{pH}=3.0-10.4)$ were used. Millipore water was used throughout.

2.3. Working Procedure. For reproducible results, improved sensitivity, and good resolution of voltammetric peaks, the working electrode was polished carefully with 1.0, 0.3 , and $0.05 \mu \mathrm{m} \alpha$-alumina on a smooth polishing cloth, and then washed in methanol. Then, it was thoroughly rinsed with water. All the reported potentials are against saturated calomel electrode (SCE).

Working solutions were prepared by diluting the stock solution as required with relevant buffer of required $\mathrm{pH}$. For $\mathrm{DPV}$, the following parameters were maintained: sweep rate, $20 \mathrm{mV} \mathrm{s}^{-1}$, pulse amplitude, $50 \mathrm{mV}$, pulse width, $60 \mathrm{~ms}$, and pulse period, $200 \mathrm{~ms}$. For analytical applications, oxidation peak $a_{1}$ was selected. All experiments were carried out at 25 $\pm 1^{\circ} \mathrm{C}$.

2.4. Analysis of Tablets. Ten tablets of MMF were powdered in a mortar. A portion of the powder equivalent to $2.5 \mathrm{mM}$ MMF was transferred into a $100 \mathrm{~mL}$ volumetric flask and completed to volume with methanol and water mixture $(50: 50)$. The contents of the flask were sonicated for $10 \mathrm{~min}$ to affect complete dissolution. Appropriate solutions were prepared by taking suitable aliquots of the clear supernatant liquid and diluting them with supporting electrolyte. To study the accuracy of the proposed method and to check the interferences from excipients used in the dosage form, recovery experiments were carried out. The content of the drug in the tablet was determined from the calibration graph or regression equation.

\subsection{Determination of MMF in Human Urine and Plasma} Samples. Spiked urine samples were obtained by treating $0.9 \mathrm{~mL}$ aliquots of urine with $100 \mu \mathrm{L}$ MMF standard solution $(2.5 \mathrm{mM})$ to obtain $250 \mu \mathrm{M}$ MMF. A suitable amount of aliquot of spiked urine was diluted with phosphate buffer (without any pretreatment) to prepare appropriate sample

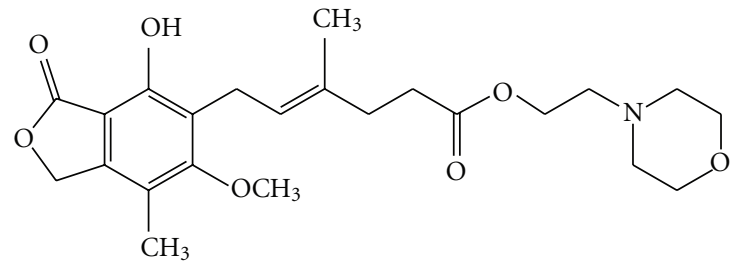

FIGURE 1: Structure of MMF.

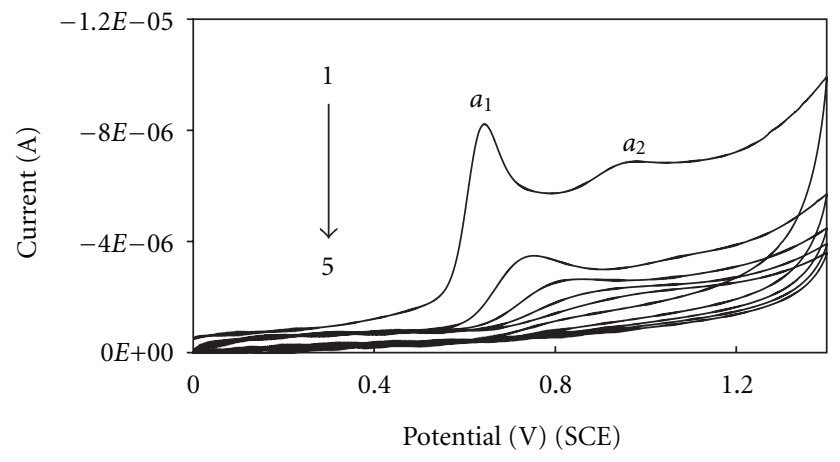

FIGURE 2: Multisweep cyclic voltammograms of $1.25 \times$ $10^{-4} \mathrm{MMMF}$ in phosphate buffer of $6.0 \mathrm{pH}$ at a scan rate $100 \mathrm{mV} \mathrm{s}^{-1}$.

solutions and differential pulse voltammograms were as recorded under optimized conditions.

Serum samples, obtained from healthy individuals (after having obtained their written consent), were stored frozen until assay. For the determination of MMF in plasma, $500 \mu \mathrm{L}$ MMF solutions $(2.5 \mathrm{mM})$ were added to $500 \mu \mathrm{L}$ of untreated plasma. The mixture was vortexed for $30 \mathrm{~s}$. In order to precipitate the plasma proteins, the plasma samples were treated with $250 \mu \mathrm{L}$ perchloric acid (15\%). After that, the mixture was vortexed for further $30 \mathrm{~s}$ and then centrifuged at $5000 \mathrm{rpm}$ for $5 \mathrm{~min}$. Appropriate volume of supernatant liquor was transferred in the voltammetric cell containing phosphate buffer of $\mathrm{pH} 6.0$ and voltammograms were recorded. The voltammograms of samples without MMF did not show any signal that can interfere with the direct determination. The content of the drug in plasma/spiked urine sample was determined referring to the calibration graph or regression equation.

\section{Results and Discussion}

3.1. Electro-Oxidation of MMF. The structure of MMF is shown in Figure 1. Cyclic voltammogram of $1.25 \times 10^{-4} \mathrm{M}$ MMF in phosphate buffer of $\mathrm{pH} 6.0$ at a sweep rate of $100 \mathrm{mV} \mathrm{s}^{-1}$ exhibited two anodic peaks at $0.631 \mathrm{~V}$ with a peak current of $7.868 \mu \mathrm{A}$ and at $0.921 \mathrm{~V}$ with a peak current of $7.292 \mu \mathrm{A}$, respectively. No peak was observed in the reverse scan suggesting that the oxidation process was irreversible in nature. The multisweep cyclic voltammograms of MMF in phosphate buffer of $\mathrm{pH} 6.0$ at the scan rate of $100 \mathrm{mV} \mathrm{s}^{-1}$ are shown in Figure 2. The significant decrease in peak current was noticed upon successive cyclic voltammetric 
TABLE 2: Effects of interferents on differential pulse voltammetric response of $20 \mu \mathrm{M}$ MMF at GCE.

\begin{tabular}{|c|c|c|c|c|}
\hline Interferent & Concentration $(\mu \mathrm{M})$ & Current $(\mu \mathrm{A})$ & Signal change $(\mu \mathrm{A})$ & $\mathrm{RSD}^{*}(\%)$ \\
\hline MMF (no interferent) & 20 & 0.610 & - & - \\
\hline Ascorbic acid & 200 & 0.596 & -0.014 & 1.91 \\
\hline Glucose & 400 & 0.618 & +0.008 & 1.57 \\
\hline Magnesium stearate & 200 & 0.619 & +0.009 & 1.55 \\
\hline Talc & 400 & 0.605 & -0.005 & 1.46 \\
\hline Acacia powder & 400 & 0.607 & -0.003 & 2.05 \\
\hline Starch & 200 & 0.603 & -0.007 & 1.65 \\
\hline
\end{tabular}

* Average of 5 determinations.

TABLE 3: Results of analysis of MMF in pharmaceutical samples.

\begin{tabular}{lcc}
\hline Tablet & Baxmune $^{\mathrm{a}}$ & Mycept $^{\mathrm{b}}$ \\
\hline Labeled claim (mg) & 500 & 500 \\
Amount found (mg) & 494 & 490 \\
Recovery (\%) & 98.8 & 98.0 \\
RSD $^{c}$ (\%) & 1.74 & 1.89 \\
Pure MMF added to tablet solution (mg) & 20 & 20 \\
Amount found (mg) & 19.75 & 20.20 \\
Recovery (\%) & 98.75 & 101.0 \\
RSD $^{c}(\%)$ & 1.32 & 1.29 \\
\hline
\end{tabular}

${ }^{a}$ Marketed by Ranbaxy laboratories.

${ }^{\mathrm{b}}$ Marketed by Panacea biotec.

${ }^{c}$ Average of 6 determinations.

sweeps. This phenomenon might be attributed to the fouling of the electrode surface due to adsorption of MMF or its oxidation product on the electrode surface [17]. To check the adsorption characteristics and to examine the reversibility of the first peak, another experiment was carried out by reversing the cycle in the potential range of $0.2-0.8 \mathrm{~V}$. But, we did not notice any peak in the reverse scan indicating the irreversibility of the first peak. Further, the peak currents were found to decrease in successive cycles thereby revealing the adsorption of the oxidized product on the electrode surface. Therefore, the voltammograms corresponding to the first cycle were considered. Among two anodic peaks $a_{1}$ and $a_{2}$, peak $a_{1}$ was considered for further investigation as it was sharper and well defined with higher peak current.

3.2. Effect of $p H$. Electro oxidation of $1.25 \times 10^{-4} \mathrm{M} \mathrm{MMF}$ was studied in phosphate buffer in the $\mathrm{pH}$ range of 3.0-10.0 by cyclic voltammetry (Figure 3 ). The potential of peak $a_{1}$ was noticed to be shifted to less positive values up to $\mathrm{pH}$ 7.0 and then became almost $\mathrm{pH}$ independent (Figure 3) with weak and ill-defined peaks, beyond $\mathrm{pH}$ 7.0. Basically, two linear regions were obtained; one in the $\mathrm{pH}$ range of 3.0-7.0 with a slope of $56 \mathrm{mV} / \mathrm{pH}$ suggesting the number of electrons to be equal to that of protons taking part in the electrode reaction [18] and another one in the $\mathrm{pH}$ range of 7.0-10.0 with a slope of $8.1 \mathrm{mV} / \mathrm{pH}$. The intersection of these lines was located around $\mathrm{pH} 8$ which is close to the $\mathrm{pKa}$ value of 8.5 for phenolic moiety of MMF [19]. The first trend

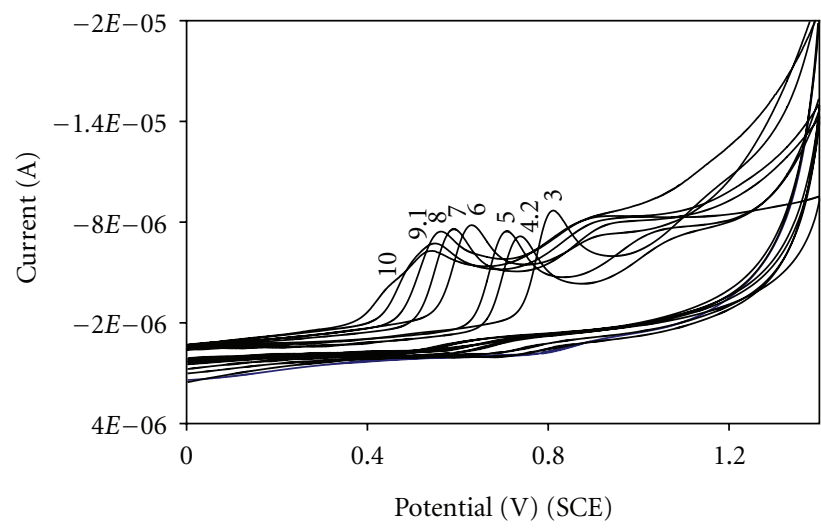

FIGURE 3: Cyclic voltammograms of $1.25 \times 10^{-4} \mathrm{MMMF}$ in phosphate buffers of different $\mathrm{pH}$ at a scan rate of $100 \mathrm{mV} \mathrm{s}^{-1}$.

noticed could be due to the oxidation of deprotonated form of MMF. A prewave was observed on more basic $\mathrm{pH}$. This was attributed to formation of aldehyde from alcohol side chain [20] which in turn was formed due to the cleavage of the lactone ring. Further, highest peak intensity (for peak $a_{1}$ ) was noticed at pH 6.0 and then decreased continuously with further increase in $\mathrm{pH}$. Hence, phosphate buffer of $\mathrm{pH} 6.0$ was selected as the supporting electrolyte for further studies.

3.3. Effect of Scan Rate. The effect of scan rate on electrooxidation of $1.25 \times 10^{-4} \mathrm{M}$ MMF in the range of 10 $800 \mathrm{mV} \mathrm{s}^{-1}$ was examined in phosphate buffer of $\mathrm{pH} 6.0$ by cyclic voltammetry (Figure 4 ). The plot of the peak current versus values of square root of scan rate $\left(10-350 \mathrm{mV} \mathrm{s}^{-1}\right)$ revealed a linear relationship $\left(r^{2}=0.9912\right)$ indicating the electrooxidation to be a diffusion-controlled process [21] and the same can be represented using the equation shown below:

$$
i_{\mathrm{pa}}(\mu A)=0.548 \nu^{1 / 2}\left(\mathrm{mV} \mathrm{s}^{-1}\right)-0.431 .
$$

Therefore, we propose that the electrooxidation of MMF is solution process in the scan rate range of $10-350 \mathrm{mV} \mathrm{s}^{-1}$ while it is surface process in the scan rate range of $400-800$ $\mathrm{mV} \mathrm{s}^{-1}$.

The peak potential was found to be linearly shifted to more positive values with increase in scan rate. A linear 
TABLE 4: Results of analysis of MMF in spiked urine and serum samples.

\begin{tabular}{lcccc}
\hline MMF added $(\mu \mathrm{M})$ & $n$ & Amount found $(\mu \mathrm{M})$ & Average recovery $(\%)$ & \\
\hline 5 & & Urine samples $(\%)$ \\
10 & 4 & 4.98 & 99.60 & 1.68 \\
20 & 4 & 9.95 & 99.50 & 1.22 \\
40 & 4 & 20.04 & 100.02 & 1.83 \\
\hline & 4 & 39.90 & 99.75 & \\
\hline 5 & & Serum samples & 98.60 \\
10 & 4 & 4.93 & 96.80 & 2.13 \\
20 & 4 & 9.68 & 96.40 & 2.29 \\
40 & 4 & 19.28 & 97.72 \\
\hline
\end{tabular}

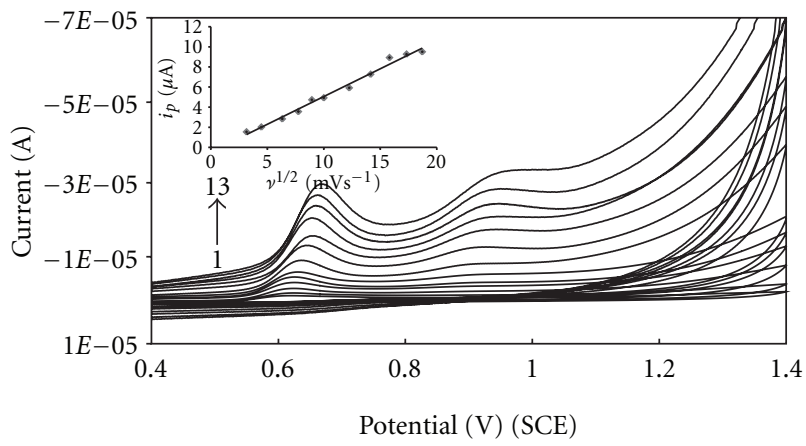

Figure 4: Cyclic voltammograms of $1.25 \times 10^{-4} \mathrm{M}$ MMF in phosphate buffer of $\mathrm{pH} 6.0$ on GCE at different scan rates: (1) 10, (2) 20, (3) 40, (4) 60, (5) 80, (6) 100, (7) 200, (8) 300, (9) 400, (10) 500, (11) 600, (12) 700, and (13) $800 \mathrm{mV} \mathrm{s}^{-1}$. Insert: peak current versus square root of scan rate in the scan rate range $10-350 \mathrm{mV} \mathrm{s}^{-1}$.

Randles-Seveik plot ( $i_{p}$ versus $v$ ) was obtained (figure not shown) in the scan rate of $400-800 \mathrm{mV} \mathrm{s}^{-1}\left(r^{2}=0.9904\right)$ according to the equation:

$$
i_{\mathrm{pa}}(\mu A)=0.021 \nu\left(\mathrm{mV} \mathrm{s}^{-1}\right)+2.706,
$$

indicating that the electrochemical behaviour of MMF on GCE seems limited by adsorption [22]. Linear relationship was observed between $E_{\mathrm{pa}}$ and scan rate was observed with a correlation coefficient of 0.9887 according to the equation shown below:

$$
E_{\mathrm{pa}}(\mathrm{mV})=0.091 \nu\left(\mathrm{mV} \mathrm{s}^{-1}\right)+620.310 .
$$

3.4. Electrochemical Oxidation Mechanism. The first oxidation peak noticed in MMF could be attributed to oxidation occurring at phenolic $-\mathrm{OH}$ which is similar to that observed in vanillylmandelic acid [23] and salbutamol [24] followed by a nucleophilic attack at the para position to $\mathrm{OH}$ group by either water molecule or methanol. The second oxidation peak observed was attributed to oxidation of enolic $-\mathrm{OH}$ group. The above mechanism was proposed based on the plot of $E_{p}$ versus $\mathrm{pH}$ which gave a slope of $56 \mathrm{mV} / \mathrm{pH}$ indicating the participation of equal number of electrons and protons in electrooxidation process [18]. A probable reaction mechanism for the oxidation of MMF is shown in Scheme 1. In order to confirm this, bulk electrolysis was performed using working electrode of high surface area for $6 \mathrm{~h}$ at a fixed potential of $1.2 \mathrm{~V}$. For this, an initial overall concentration of $1 \mathrm{mM}$ MMF was maintained in $40 \mathrm{~mL}$ of phosphate buffer solution. The charge passed was $1.150 \times 10^{-1} \mathrm{C}$, and the end current was $-1.004 \times 10^{-5} \mathrm{~A}$. The products were isolated and subjected to mass spectral analysis which showed three peaks at $\mathrm{m} / \mathrm{z}$ values of 334,320 , and 302, respectively, corresponding to the fragmentation peaks of oxidation products of MMF namely, $a, b$, and $c$, respectively (Scheme 1).

3.5. Analytical Features. Differential pulse voltammetric technique provides higher sensitivity and better peak resolution compared to cyclic voltammetry for studying the electrochemical behavior of electroactive compounds. Therefore, we used this technique for the determination of MMF. The differential pulse voltammogram of MMF at different concentrations in phosphate buffer of pH 6.0 at GCE are shown in Figure 5. Under the optimized conditions, the calibration graph for MMF showed the linearity in the concentration range of $1.5 \times 10^{-7}-7.5 \times 10^{-4} \mathrm{M}$. The characteristics of calibration graph are recorded in Table 1. Validation of the procedure for quantitative determination of MMF was examined via evaluation of the limit of detection (LOD) and limit of quantification (LOQ). The LOD and LOQ values were calculated using the equations shown below:

$$
\mathrm{LOD}=\frac{3 s}{m}, \quad \text { LOQ }=\frac{10 s}{m}
$$

where $s$ is the standard deviation of the peak currents (five runs) and $m$ is the slope of the calibration curve [25]. LOD and LOQ were found to be $1.48 \times 10^{-7}$ and $4.94 \times 10^{-7} \mathrm{M}$, respectively. The repeatability of the current measurement was calculated from five independent runs of $1.25 \times 10^{-4} \mathrm{M}$ MMF solution. The RSD values for Interday assay and intraday assay were calculated. The corresponding 
<smiles>COc1c(C)c2c(c(O)c1C/C=C(\C)CCC(=O)CCCN1CCOCC1)C(=O)OC2</smiles><smiles>COc1c(C)c2c(c(O)c1C/C=C(\C)CCC(=O)CCCN1CCOCC1)C(=O)OC2</smiles><smiles>COC1=C(C/C=C(\C)CCC(=O)CCCN2CCOCC2)C(=O)C2=C(COC2=O)C1(C)O</smiles>

(b)<smiles>COC1=C(C)C2=C(C(=O)OC2)C(=O)/C1=C/C=C(\C)CCC(=O)CCCN1CCOCC1</smiles>

(c)

Scheme 1: Probable oxidation pathway for the electrochemical oxidation of MMF.

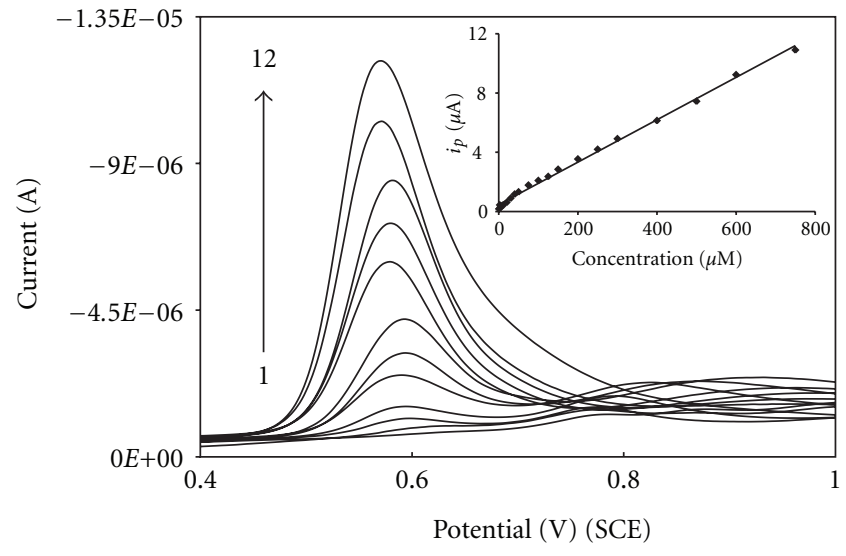

FIGURE 5: Differential pulse voltammogram of MMF at different concentrations: (1) 0.5 , (2) 2.5, (3) 10, (4) 25, (5) 50, (6) 100, (7) 150, (8) 300, (9) 400, (10) 500, (11) 600, and (12) $750 \mu \mathrm{M}$. Insert: calibration plot for the determination of MMF.

values shown in Table 1 indicated good reproducibility of the results.

3.6. Effects of Interferents. The selectivity of the proposed method was investigated by studying the effects of interferents, namely, glucose, magnesium stearate, starch, acacia powder, ascorbic acid, and talc on electrochemical determination of MMF. For this, we have recorded differential pulse voltammogram of $20 \mu \mathrm{M}$ MMF in presence of different concentrations of interferents. The results of effects of interferents on peak current of MMF are shown in Table 2. It was noticed that the ascorbic acid, magnesium stearate, and starch did not interfere up to 10 -fold excess while glucose, talc, and acacia powder exerted no effect up to 20-fold excess. Therefore, the proposed method offers good selectivity for the determination of MMF.

3.7. Pharmaceutical Applications (Tablet Analysis). The developed DPV method was applied successfully for the assay of MMF in tablets. The results of analysis of MMF recorded in Table 3 were found to be satisfactory. Further, recovery studies were carried out by standard addition method. For this, known quantities of pure MMF were mixed with definite amounts of preanalyzed formulations and the mixtures were analyzed as before. The total amount of the drug was then determined, and the amount of the added drug was calculated by difference. The average percent recoveries obtained were found to be quantitative indicating good recovery of the drug (Table 3 ).

3.8. Determination of MMF in Urine and Plasma Samples. The practical analytical application of the method was further established by determining MMF in human urine samples without any preliminary treatment. The recoveries from urine samples were examined by spiking drug-free urine with known amounts of MMF. The calibration graph was used to determine the concentration of MMF in urine samples. The results of analysis are listed in Table 4 . The average recovery was observed to be higher than $99.5 \%$ and 
the RSD values were less than $2.1 \%$. These values indicated good recovery and reproducibility of the results.

The applicability of the proposed method was further examined by analyzing MMF in plasma samples employing GCE. Serum samples were spiked with known amounts of MMF and further diluted with supporting electrolyte. The amount of MMF in serum samples was determined by referring to the calibration plot. The results incorporated in Table 4 indicated good recovery of MMF.

\section{Conclusions}

The electrochemical behavior of MMF at GCE was investigated for the first time. MMF was found to undergo oxidation irreversibly in phosphate buffer of $\mathrm{pH}$ 6.0. The proposed differential pulse voltammetric procedure was employed successfully to determine MMF in tablets and biological samples. Since, the method is simple, fast, and inexpensive, it could be readily adopted in clinical and quality control laboratories.

\section{Acknowledgments}

The authors thank the University Grants Commission, New Delhi, for financial assistance (F. no. 34/374/2008 (SR) dated 30-12-2008). We are also grateful to the authorities of the Karnatak University, Dharwad, for providing the necessary facilities.

\section{References}

[1] B. Fulton and A. Markham, "Mycophenolate mofetil: a review of its pharmacodynamic and pharmacokinetic properties and clinical efficacy in renal transplantation," Drugs, vol. 51, no. 2, pp. 278-298, 1996.

[2] D. C. Brennan and M. J. Koch, "Is mycophenolate mofetil really necessary in renal transplantation? A review of the MYSS follow-up study," Nature Clinical Practice Nephrology, vol. 3, no. 11, pp. 602-603, 2007.

[3] P. Mathieu, M. Carrier, M. White et al., "Effect of mycophenolate mofetil in heart transplantation," Canadian Journal of Surgery, vol. 43, no. 3, pp. 202-206, 2000.

[4] T. M. Manzia, N. D. L. Carino, G. Orlando et al., "Use of mycophenolate mofetil in liver transplantation: a literature review," Transplantation Proceedings, vol. 37, no. 6, pp. 26162617, 2005.

[5] A. Zuckermann, T. Birsan, S. Thaghavi et al., "Mycophenolate mofetil in lung transplantation," Transplantation Proceedings, vol. 30, no. 4, pp. 1514-1516, 1998.

[6] R. W. Gruessner, D. E. Sutherland, M. B. Drangstveit, L. Wrenshall, A. Humar, and A. C. Gruessner, "Mycophenolate mofetil in pancreas transplantation," Transplantation, vol. 66, no. 3, pp. 318-323, 1998.

[7] M. Cantarovich, N. W. Brown, M. H. H. Ensom et al., "Mycophenolate monitoring in liver, thoracic, pancreas, and small bowel transplantation: a consensus report," Transplantation Reviews, vol. 25, no. 2, pp. 65-77, 2011.

[8] L. Johnston, M. Florek, R. Armstrong et al., "Sirolimus and mycophenolate mofetil as GVHD prophylaxis in myeloablative, matched-related donor hematopoietic cell transplantation," Bone Marrow Transplantation. In press.
[9] V. Sepe, C. Libetta, M. G. Giuliano, G. Adamo, and A. D. Canton, "Mycophenolate mofetil in primary glomerulopathies," Kidney International, vol. 73, no. 2, pp. 154-162, 2008.

[10] A. L. Rao, P. V. Srinivas, and J. V. L. N. S. Rao, "A new validated RP-HPLC method for the estimation of mycophenolate mofetil in pure and tablet dosage form," Journal of Pharmaceutical Research and Health Care, vol. 2, no. 3, pp. 266-269, 2010.

[11] N. Sugioka, H. Odani, T. Ohta, H. Kishimoto, T. Yasumura, and K. Takada, "Determination of a new immunosuppressant, mycophenolate mofetil, and its active metabolite, mycophenolic acid, in rat and human body fluids by high-performance liquid chromatography," Journal of Chromatography B, vol. 654, no. 2, pp. 249-256, 1994.

[12] U. D. Renner, C. Thiede, M. B. User, G. Ehninger, and H. M. Thiede, "Determination of mycophenolic acid and mycophenolate mofetil by high-performance liquid chromatography using postcolumn derivatization," Analytical Chemistry, vol. 73, no. 1, pp. 41-46, 2001.

[13] I. Tsina, M. Kaloostian, R. Lee, T. Tarnowski, and B. Wong, "High-performance liquid chromatographic method for the determination of mycophenolate mofetil in human plasma," Journal of Chromatography B, vol. 681, no. 2, pp. 347-353, 1996.

[14] M. Platzer, K. Jahn, J. Wohlrab, and R. H. H. Neubert, "Quantification of mycophenolate mofetil in human skin extracts using high-performance liquid chromatography-electrospray mass spectrometry," Journal of Chromatography B, vol. 755, no. 1-2, pp. 355-359, 2001.

[15] S. Verma, H. Gupta, O. Alam, P. Mullick, N. Siddiqui, and S. A. Khan, "Spectrophotometric methods for the estimation of mycophenolate mofetil," Journal of Applied Spectroscopy, vol. 76, no. 6, pp. 876-882, 2009.

[16] V. P. Tripodi, S. E. Lucangioli, C. L. Barbara, V. G. Rodríguez, and C. N. Carducci, "Analysis of immunosuppressive drugs and their pharmaceuticals by micellar electrokinetic chromatography," Chromatographia, vol. 54, no. 1-2, pp. 93-98, 2001.

[17] C. R. Raj, F. Kitamura, and T. Ohsaka, "Square wave voltammetric sensing of uric acid using the self-assembly of mercaptobenzimidazole," Analyst, vol. 127, no. 9, pp. 11551158, 2002.

[18] R. N. Goyal, N. Bachheti, A. Tyagi, and A. K. Pandey, "Differential pulse voltammetric determination of methylprednisolone in pharmaceuticals and human biological fluids," Analytica Chimica Acta, vol. 605, no. 1, pp. 34-40, 2007.

[19] http://www.rxlist.com/cellcept-drug.htm/.

[20] A. J. Motheo, G. Tremiliosi-Filho, E. R. Gonzalez, K. B. Kokoh, J. M. Léger, and C. Lamy, "Electrooxidation of benzyl alcohol and benzaldehyde on a nickel oxy-hydroxide electrode in a filter-press type cell," Journal of Applied Electrochemistry, vol. 36, no. 9, pp. 1035-1041, 2006.

[21] A. J. Bard and L. R. Faulkner, Electrochemical Methods: Fundamentals and Applications, John Wiley \& Sons, New York, NY, USA, 1980.

[22] P. Monk, Fundamentals of Electroanalytical Chemistry, John Wiley \& Sons, New York, NY, USA, 2001.

[23] Q. Li, C. B. Mcauley, and R. G. Compton, "Electrooxidative decarboxylation of vanillylmandelic acid: voltammetric differentiation between the structurally related compounds homovanillic acid and vanillylmandelic acid," Journal of Physical Chemistry B, vol. 114, no. 29, pp. 9713-9719, 2010.

[24] K. A. Sagar, M. R. Smyth, and R. Munden, "Voltammetric study of salbutamol and application to its determination in 
a tablet dosage form and dissolution profiles for the dosage form," Journal of Pharmaceutical and Biomedical Analysis, vol. 11, no. 7, pp. 533-540, 1993.

[25] S. Skrzypek, W. Ciesielski, A. Sokolowski, S. Yilmaz, and D. Kazmierczak, "Square wave adsorptive stripping voltammetric determination of famotidine in urine," Talanta, vol. 66 , no. 5 , pp. 1146-1151, 2005. 


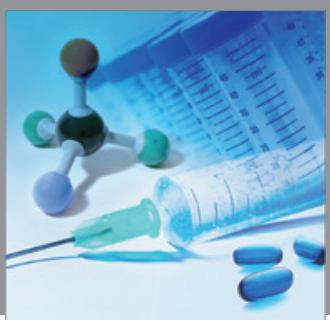

International Journal of

Medicinal Chemistry

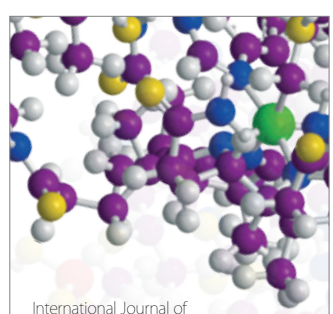

Carbohydrate Chemistry

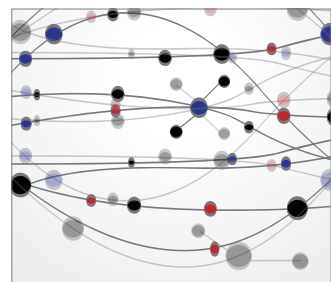

The Scientific World Journal
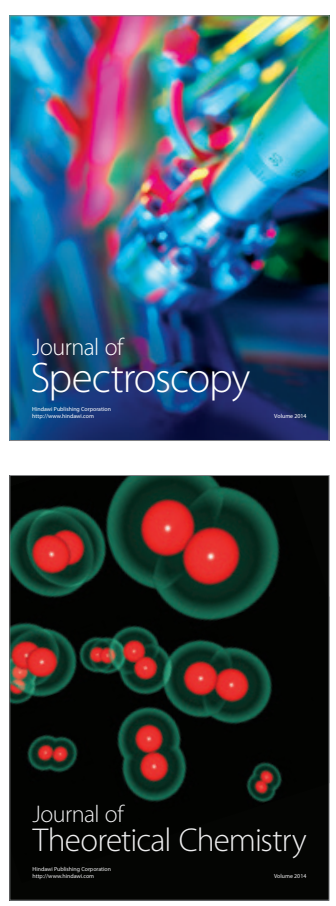
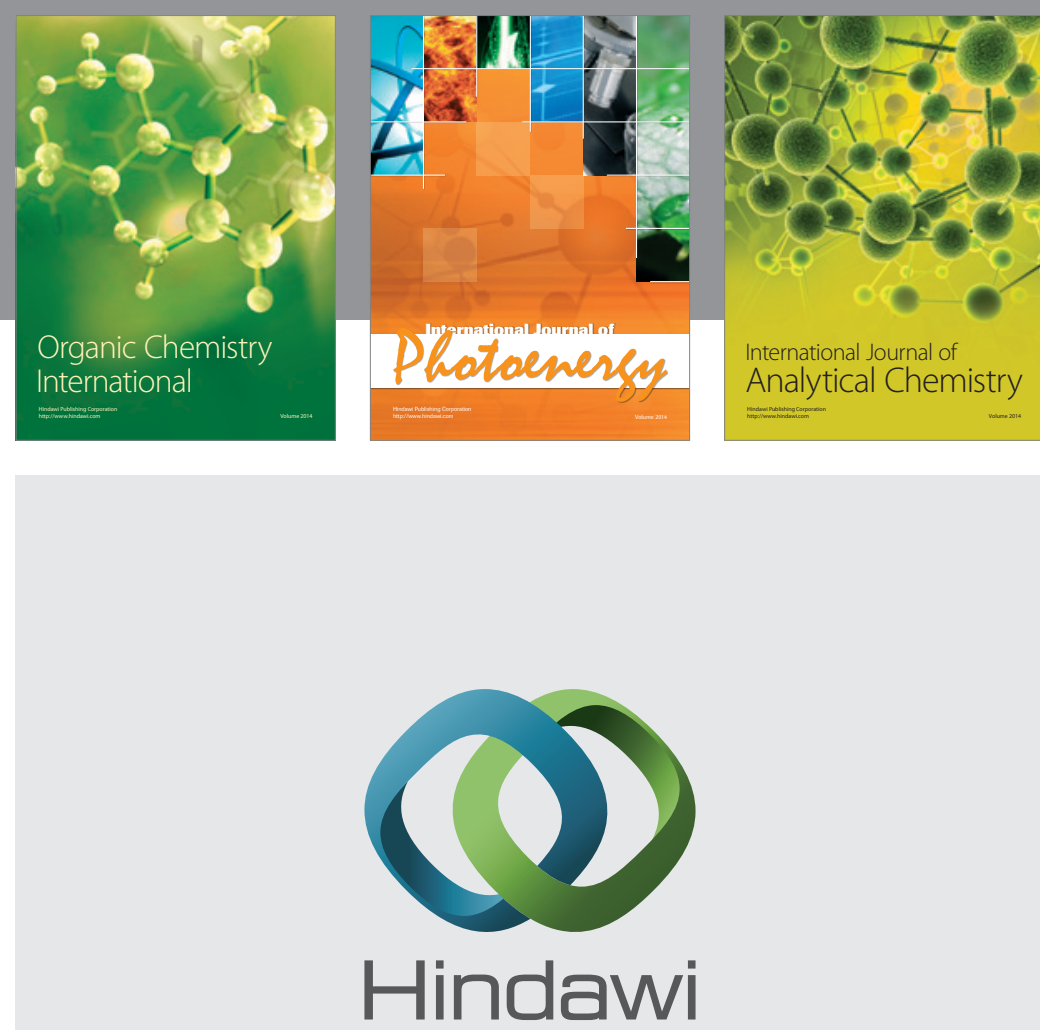

Submit your manuscripts at

http://www.hindawi.com
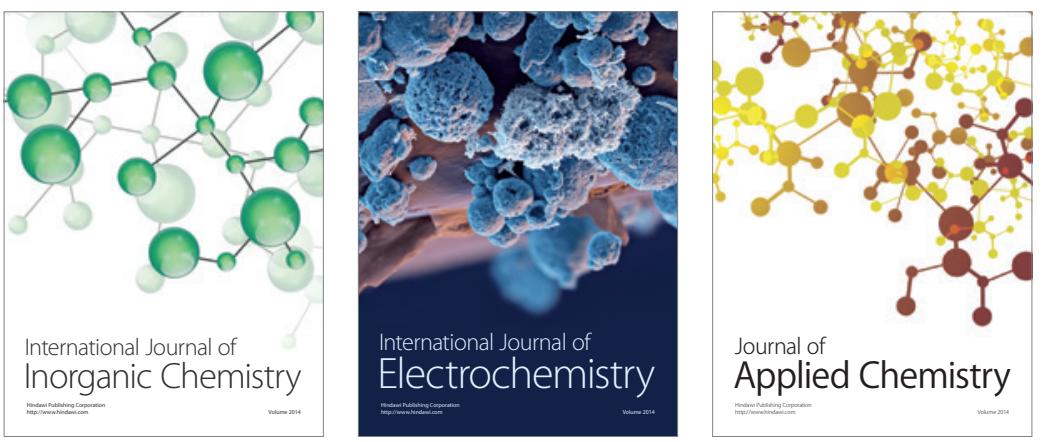

Journal of

Applied Chemistry
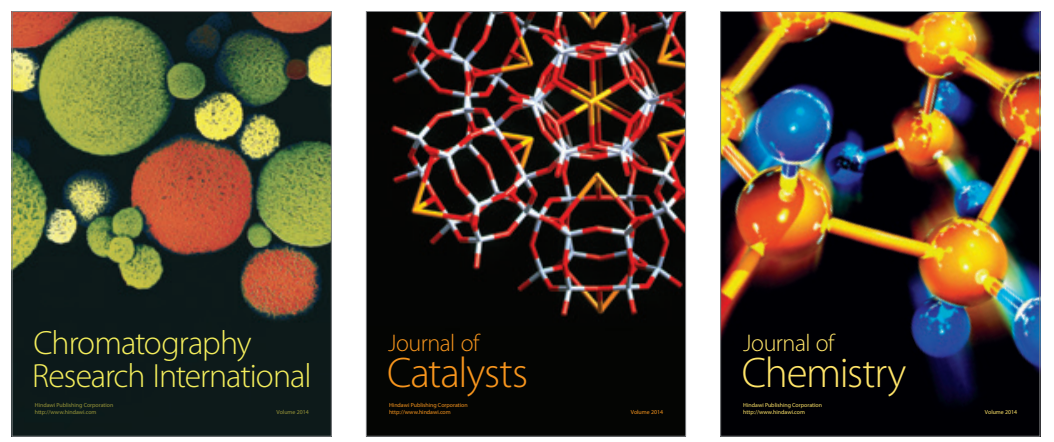
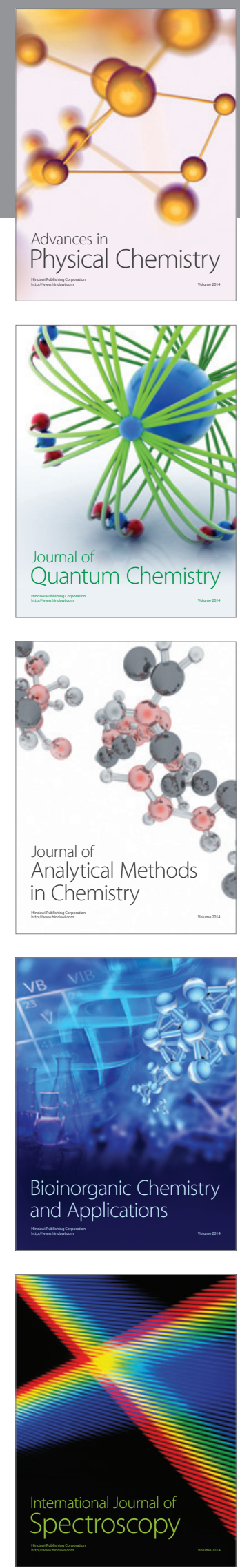